\title{
Coupling a Particle Beam Interface Directly to a Quadrupole Ion Trap Mass Spectrometer
}

\author{
Mark E. Bier, Paul C. Winkler, and Jack R. Herron \\ Finnigan MAT Corporation, San Jose, California, USA
}

\begin{abstract}
A particle beam interface has been coupled to a quadrupole ion trap mass spectrometer. The system allows the collection of electron ionization mass spectra from analyte in solution. The interface incorporates a pneumatic nebulizer, a heated desolvation chamber, and a three-stage separator region. Additional helium, for improved performance, is added through stage 3 . The particles formed in the interface are separated from solvent molecules and are transferred directly to the ion trap where they are expected to collide with the hot hyperbolic surface of the end cap. The end cap serves both as a heated target used to vaporize the particles and as an ion-trapping electrode. Mass analysis is achieved with the mass-selective instability scan supplemented with resonance ejection. Electron ionization spectra from 100 ng of caffeine [molecular weight (MW) - 194]; 1-naphthalenol methylcarbamate (carbaryl) (MW $=201), 17 \alpha$-hydroxyprogesterone (MW $=330)$, and reserpine ( $M W=608$ ) are shown using sampling by a segmented flow analysis. Some charge exchange is evident with methanol as well as self-chemical ionization at higher analyte levels. The interface shows a nonlinear caffeine calibration curve for analyte amounts below $30 \mathrm{ng}$ and a more linear response at higher amounts. Caffeine was detected at $25 \mathrm{pmol}(5 \mathrm{ng})$, with a signal-to-noise ratio of 50, 20- $\mu \mathrm{L}$ loop, full scan. (J Am Soc Mass Spectrom 1993, 4, 38-46)
\end{abstract}

$\mathrm{P}$ article beam (PB) mass spectrometry of analyte in liquid solutions was first described in 1975 by Greene $[1,2]$. A variation of this system was later developed to provide library-searchable electron ionization (EI) spectra from compolsnds eluting from a liquid chromatography (LC) column [3-6]. Other ionization techniques, such as chemical ionization (CI) and fast-atom bombardment (FAB) [7-9], have also been demonstrated with the $\mathrm{PB}$ interface.

Before the PB interface, only membrane [10-12] and moving belt $[13-17]$ interfaces allowed the generation of EI and CI spectra from an analyte in solution, and only recently has a low-flow direct liquid inlet interface [18] been used to acquire EI spectra. Dimethyl vinyl silicone polymer membrane interfaces have shown high sensitivity but primarily for volatile nonpolar molecules, and thus one of their main uses has been in the analysis of volatile organic compounds in water and in reaction monitoring [19]. The moving belt interface has been used to observe analytes in high percentages of water [20] and has been used for detection in the picogram range [15], but it can have memory effects, and some workers consider it cumbersome [6]. Other techniques, such as thermospray [21-23], electrospray [24-26], and flow FAB [27-29], are used as on-line continuous LC interfaces, but they typically

Address reprint requests to Mark E. Bier, Finnigan MAT Corporation, 355 River Oaks Parkway, San Jose, CA 95134. produce "CI-like" mass spectra and give little structural information. In the past few years, however, experiments using electrospray [30] and thermospray [31] have been conducted using collision-activated dissociation for improved structural analysis.

Although improvements have been made to the PB interface [5, 32], the concept of using stages of momentum separation to enrich the beam with particles and to remove solvent has remained unchanged. In PB systems, a liquid solution is nebulized into microdroplets that are partially desolvated and accelerated through a nozzle. Once through the nozzle, high-velocity particles are momentum separated from solvent by skimmers and are then transferred to the ion source. The enrichment region traditionally consists of two stages of momentum separations [3-6].

There are several limitations found with the current PB interfaces. The analyte response is observed to change owing to a coelution carrier process [33]. The analyte response is reduced at high percentages of the solvent water [4], and nonlinear calibration curves have been observed [4,5]; however, even with these disadvantages, the technique is valuable because it does allow the collection of EI mass spectra from analytes in dilute solutions.

The objective of this work is to couple a three-stage $\mathrm{PB}$ interface [32] to a more solvent-sensitive mass spectrometer, the quadrupole ion trap, and produce EI mass spectra. We report a three-stage $\mathrm{PB}$ interface 
supplemented with helium coupled directly to an inexpensive ion trap mass spectrometer [34]. Particles pass directly into the ion-trapping chamber, where they are vaporized, ionized, and mass analyzed.

\section{Instrumentation and Experimental}

\section{Liquid Chromatography Pump and Injection System}

A Waters 600 MS LC system was used to introduce liquid into the PB interface. This pump uses dual pistons and is equipped with software to reduce pulsation. Helium was used to degas the solvent. A six-port Rheodyne 7125 injector with a 20- $\mu$ L loop was used for flow injection analysis, and an additional Rheodyne 7000 valve was used to divert the LC effluent from the PB interface to waste, if desired. Reagent-grade or gas chromatography/mass spectrometery (GC/MS)-grade methanol (Burdick and Jackson, Muskegon, MI) and high-performance liquid chromotography (HPLC)grade water (Mallinckrodt, Paris, KY) were used as the solvents throughout this study.

\section{Coupling a Three-Stage Particle Beam Interface to the Ion Trap}

The PB interface incorporates a pneumatic nebulizer, a heated aluminum desolvation chamber, a nozzle, a three-stage momentum separator, and a stainless steel transfer line, as shown in Figure 1. The solution is pumped through the HPLC stainless steel tubing, through a 15-cm length of fused silica capillary tubing, and into a glass concentric pneumatic nebulizer [35]. The nebulizer shears the liquid eluting at the tip into droplets, with a concentric flow of $0.6 \mathrm{~L} / \mathrm{min}$ of helium. The flow of helium through the nebulizer was measured and optimized with a calibrated rotameter (Cole Parmer Scientific, Chicago, IL). The droplets are directed toward the nozzle and desolvate as they flow through the heated desolvation chamber. A temperature controller (model ETR-9080; Ogden, Arlington Heights, IL), iron/constantan thermocouple, and two 300-W cartridge heaters are used to supply the heat to the desolvation chamber. The droplets are expected to partially desolvate, leaving only slightly solvated analyte particles. The remaining droplets and newly formed particles are seeded into the flow of helium and solvent through the nozzle. The particles are accelerated through the $0.5-\mathrm{mm}$ orifice of the nozzle (10:1 aspect ratio) and exit into the momentum separator region at or near supersonic velocities. Following along the axis of flow, the orifice diameters of skimmers 1,2, and 3 are $0.5,0.5$, and $2.5 \mathrm{~mm}$, respectively. The spacings used are $5 \mathrm{~mm}$ between the nozzle and skimmer $1,5 \mathrm{~mm}$ between skimmers 1 and 2, and $16 \mathrm{~mm}$ between skimmers 2 and 3 . Three rotary vane vacuum pumps are used to remove the solvent from the interface. A Balzers UNO 016B with a volume flow rate of $267 \mathrm{~L} / \mathrm{min}$ is used in stage 1 , an Alcatel 2008 A with a volume flow rate of $150 \mathrm{~L} / \mathrm{min}$ is used in stage 2 , and an Alcatel 2012A with a volume flow rate of 250 $\mathrm{L} / \mathrm{min}$ is used in stage 3 .

The pressures of gas in the desolvation chamber, stages 1,2 , and 3 are measured with a Bourdon tube, 1-1000-torr capacitance manometer (MKS Instruments, Andover, MA), Pirani gauge (Granville-Phillips, Boulder, $\mathrm{CO}$, convectron), and a $10^{-4}$-1-torr capacitance manometer (MKS), respectively.

The pressure difference across the nozzle of the PB interface results in the formation of a free jet expansion system. The free jet expansion consists of a barrel shock wave that encompasses the expanding axial flow and ends with a Mach disk perpendicular to the axial flow. A Mach disk shock wave is the result of gas molecules traveling faster than the speed of sound in that medium [36]. The position of the Mach disk between the nozzle and skimmer 1 is believed to be important for optimum momentum separation. The values of the desolvation chamber pressure $\left(P_{0}\right)$, the stage 1 pressure $\left(P_{1}\right)$, and the diameter of the orifice $\left(D_{n}\right)$ determine the distance from the nozzle to the Mach disk $\left(X_{\mathrm{m}}\right)$. The equation $X_{\mathrm{m}}=0.67\left(P_{0} / P_{1}\right)^{1 / 2} D_{\mathrm{n}}$ can be used to estimate this axial distance [37]. Because we have a capillary nozzle, not an orifice, we must correct for $\boldsymbol{P}_{0}$ owing to the drop in pressure within the nozzle; calculations show that the Mach disk is expected to be located approximately $50 \%$ of the distance calculated with the preceding formula.

PB interfaces may be designed to position the Mach disk beyond the first skimmer orifice in an "attached" mode or between the nuzcle and the first skimmer in a "detached" mode. The PB separator designed for these studies places the Mach disk approximately $3.5 \mathrm{~mm}$ in front of skimmer 1, and it is thus detached. In the detached Mach disk scheme, gas flow through skimmer 1 is lower, and the particle/solvent enrichment ratio is also expected to be lower. In this case, gases flow on axis through the skimmer and particle loss is expected to be high due to the distance of travel and the angular spread of the beam. In the attached scheme, the gases flow away from the axis and the shorter distance should allow for increased particle transmission. Although the attached scheme may be advantageous, we chose to increase the overall pumping efficiency at stage 1 and may have thereby sacrificed some particle enrichment. In either the attached or detached schemes, the trajectories of large particles at high velocities (high momentum) are not greatly perturbed by the gas flow lines and tend to maintain a straight path. This allows particles to be separated from the rest of the beam by the skimmers. The particle separation that occurs in stage 2 involves a Mach disk located $1.3 \mathrm{~mm}$ from the exit side of the skimmer 1 orifice, but the gas comprising this disk is less dense than the Mach disk found in stage 1 .

The ion trap requires the addition of helium for optimum performance. Helium may be added directly to the manifold chamber or the PB interface. By adding 


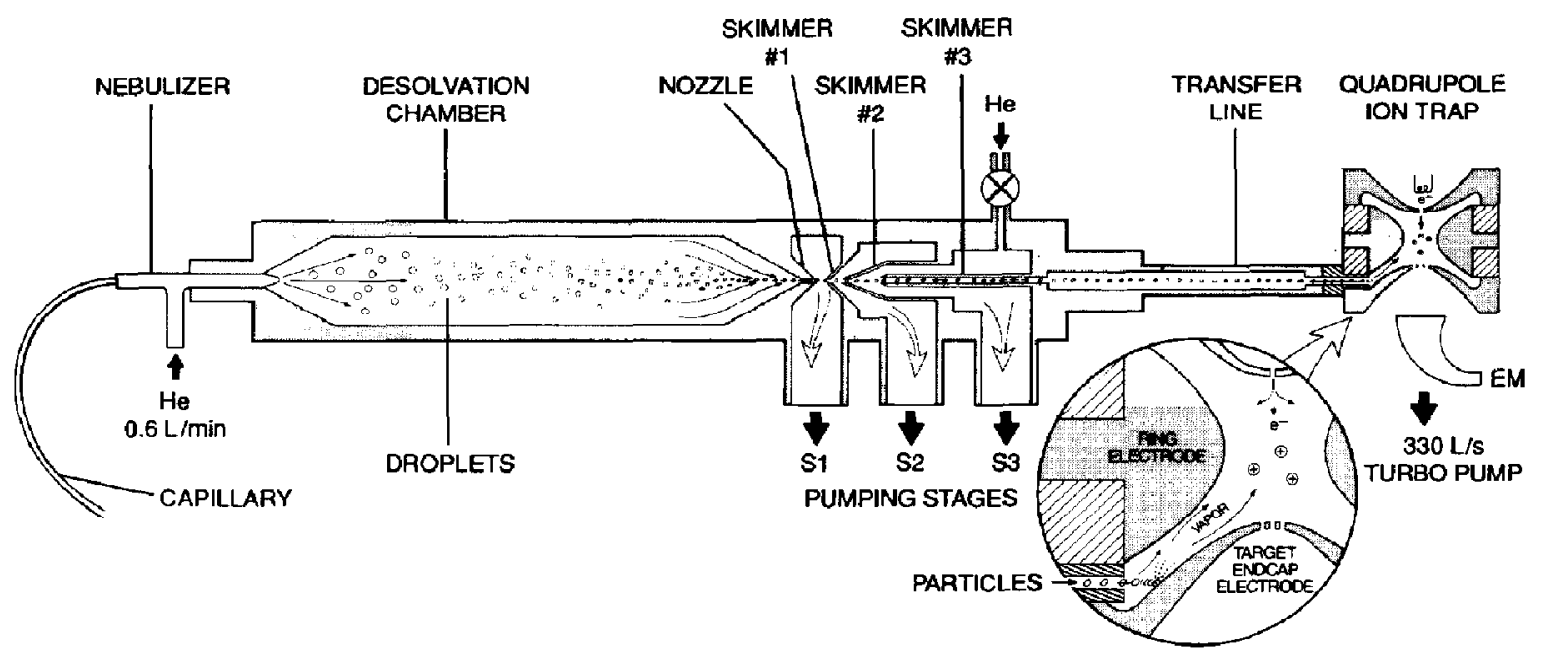

Figure 1. Three-stage PB interface coupled directly to a quadrupole ion trap mass spectrometer,

helium to stage 3, two advantages are realized: (1) A high pressure of helium (ca. 200 mtorr) reduces the amount of solvent that would otherwise flow into stage 3 from stage 2; and (2) a viscous flow condition is established from stage 3 to the rotary vane pump, thus preventing pump oil from backstreaming. The helium pressure in stage 3 was adjusted to equal approximately the pressure in stage 2 (uncorrected pressure reading). The third stage receives some solvent by diffusion through the small orifice in skimmer 2 , but the amount of solvent found in stage 3 is minimal compared with the other stages. There is no shock wave in stage 3 when operated under these conditions.

Once leaving the momentum separator region, the analyte particles are transferred to the ion trap through a stainless steel transfer line. The transfer line is sealed to the ion trap body with a polyimide (Dupont vespel) tip that is fitted into the ion trap opening normally used for a GC transfer line. The particles remaining on axis are thereby directed to the exit end cap of the quadrupole ion trap. The particles are expected to strike the hot stainless steel hyperbolic surface of the exit end cap, where the analyte is vaporized. After the analyte is vaporized, ions are formed in the ion trap by EI.

A vacuum interlock valve was added to the manifold so that the transfer line and thus the entire interface could be easily removed and isolated from the manifold chamber. Table 1 shows the typical operating conditions for the PB quadrupole ion trap system.

\section{Quadrupole Ion Trap Mass Spectrometer}

The ion trap used in this study was a modified Finnigan ITS40 prototype. The vacuum manifold was mounted above a Balzers 330-L/s turbomolecular pump backed by an Alcatel 2008A rotary vane vacuum pump. A Bayard-Alpert ionization gauge was at-
Table 1. Typical operating parameters for the particle beam/ion trap system

\begin{tabular}{lc}
\hline Liquid flow rate & $0.5 \mathrm{~mL} / \mathrm{min}$ \\
Injection loop volume & $20 \mathrm{\mu L}$ \\
Nebulizer flow rate, He & $0.6 \mathrm{~L} / \mathrm{min}$ \\
Desolvation temperature & $50^{\circ} \mathrm{C}$ \\
lon trap temperature & $170^{\circ} \mathrm{C}$ \\
Manifold temperature & $220^{\circ} \mathrm{C}$ \\
Desolvation pressure & $200-250 \mathrm{torr}$ \\
Stage 1 pressure & 3 torr \\
Stage 2 pressure & $200 \mathrm{mtorr}$ \\
Stage 3 pressure & $200 \mathrm{mtorr}$ of He \\
Ion trap pressure & $1 \mathrm{mtorr}$ of He \\
Analyzer pump speed & $330 \mathrm{~L} / \mathrm{s}$ \\
Multiplier gain & $10^{5}$ \\
\hline
\end{tabular}

Uncorrected pressure from a Pirani gauge.

tached to the manifold for pressure measurements. The ions trapped by the quadrupole field are mass analyzed using the mass-selective instability scan [38] supplemented with resonance ejection and detected with a channel electron multiplier. This ion trap was operated with a trapping-field frequency of $1.1 \mathrm{MHz}$ (applied bctween the ring electrode and the manifold) and a resonance-ejection frequency of approximately $0.524 \mathrm{MHz}\left(\beta_{z}=0.953\right)$ (applied between the end caps during mass analysis) $[38,39]$. The resonance-ejection voltage allows one to achieve at least unit mass resolution when a greater number of ions are in the trap and thus increases the dyriamic range. The amplitude for this resonance ejection $\mathrm{rf}$ was optimized by observing the intersity and resolution versus amplitude for $m / z$ 69 and 614 frum perfluorotributylamine (FC43). The resonance-ejection amplitude was set between 3 and 6 $\mathrm{V}\left[V_{\mathrm{pp}}\right.$ (volts peak-to-peak) of the waveform on one end cap with respect to manifold ground] for the work shown here. The 1-mtorr of helium added to the trap via stage 3 of the interface presumably damps the ion trajectories to the center of the trap, greatly enhancing 
the resolution and sensitivity obtained for high-mass ions [40]. The ion trap manifold was heated to a temperature of $220^{\circ} \mathrm{C}$ by a healer jacket that transfers heat to the target end cap radiantly and through conduction. A warm-up period of at least $4 \mathrm{~h}$ was used to allow the exit end cap to reach an equilibrium temperature of $170-175^{\circ} \mathrm{C}$. This temperature was measured using a thermocouple placed on the exit end cap. The exit end cap serves a dual purpose in this instrument: a heated target for vaporizing the particles and an electrode used to form the quadrupole field. The ion trap is controlled via an IBM $195 / 2$, model 30, personal computer and a Finnigan ITMS Data System, Revision B software.

Ion-molecule reactions and space charge effects are two potential problems when coupling a PB interface directly to an ion trap. Ion-molecule reactions include protonation, the formation of adducts, or charge exchange, or a combination of all three factors. "Space charge" is the term used to describe the phenomenon in which ions of the same charge are in such close proximity to each other that the trajectory of each ion is perturbed. In ion trap mass spectrometers this leads to lower resolution and thus a decreased dynamic range. To prevent space charging and ion-molecule reactions, it is desirable to have the lowest number of solvent ions in the trap. A three-stage PB interface was chosen to reduce these two types of interactions. The ion trap data system further reduces the possibility of space charge from too many analyte ions by automatically varying the ionization time. This feature keeps the number of ions below space charge conditions and thus extends the dynamic range of the instrument.

The rf amplitude was set at a high level during ionization so as to maintain a condition of instability for ions less than $m / z$ 50. The high rf level used during ionization removes low mass-to-charge ratio solvent ions from the trap (reducing the possibility of space charging and ion-molecule reactions) and protects the electron multiplier from solvent background ions (should one scan bclow $50 \mathrm{u}$ ).

\section{Tests of the Particle Beam / Quadrupole Ion Trap Mass Spectrometer}

To test the coupling of the three-stage PB interface to a quadrupole mass spectrometer, methanol was used at a flow rate of $0.5 \mathrm{~mL} / \mathrm{min}$. Visual studies of the interface after both a continuous flow of $400 \mathrm{ng} / \mathrm{s}$ of caffeine and injections of methylene blue gave qualitative indications of the PB shape and the locations of particle loss. Four compounds were used to assess the quality of the EI spectra produced. The EI spectra of caffeine, carbaryl, 17 $\alpha$-hydroxyprogesterone, and reserpine were acquired from injections of $100 \mathrm{ng}$ of the individual compounds. A calibration curve was obtained for samples between 1 and $500 \mathrm{ng}$ of caffeine to ascertain the linearity of the system response. Prelimi- nary tests were also conducted using neat water as the solvent and caffeine as the analyte.

\section{Results and Discussion}

\section{Effects of the Helium Flow Rate Through the Nebulizer}

Increasing the flow of helium through the nebulizer increased the PB desolvation chamber pressure from 170 to 360 torr and resulted in a change of the ion signal. 'The effect of changing the nebulizer helium flow rate and thus chamber pressure on signal intensity is shown in Figure 2. The curve is asymmetric and has a relatively narrow window of optimum performance between 180 and 250 torr. A methanol flow rate of $0.5 \mathrm{~mL} / \mathrm{min}$ and a helium flow rate of $0.5 \mathrm{~L} / \mathrm{min}$ correspond to a desolvation pressure of 200 torr in this PB interface. At too low a helium flow rate, the nebulizer was observed to be inefficient, and the sensitivity was reduced. The sensitivity decrease may be partially due to the formation of large, low-velocity droplets that are difficult to desolvate and transmit to and through the nozzle. At too high a helium flow rate, the signal intensity is decreased. The reduced signal at high pressures is not well understood but may be due to an increase in particle dispersion [41]. At typical operating helium flow rates through the nebulizer, helium reaches the ion trap manifold from the nebulization process in sufficient quantity to produce a pressure of ca. $4 \times 10^{-7}$ torr (corrected) in the manifold.

\section{Particle Deposits in the Particle Beam Interface}

Significant particle loss was observed in the region between the nozzle and skimmer 1, as has also been found by others [4]. This observation was made after flowing $400 \mathrm{ng} / \mathrm{s}$ of caffeine into the interface for several hours and then viewing the skimmers. The interface was then cleaned and the flow changed to pure methanol. Methylene blue in methanol was next injected in $20-\mu \mathrm{L}$ plugs to confirm the earlier caffeine observations. In both of these experiments, particle deposits were found around the orifice of skimmer 1. A stereoscopic microscope was used to determine the outside diameter of the annulus of aralyte particles. Both the white (caffeine) and the blue arnulus (methylene blue) had an outside diameter of approximately $1.5 \mathrm{~mm}$, which is three times the diameter of the orifice. These experiments demonstrate that a significant amount of analyte is lost in the first stage of the interface. Deposits were observed elsewhere in the interface and gave indications of analyte loss primarily before skimmer 2 . In one particular examination of the inside of the conical surface of skimmer 1, a deposit of particles in the shape of a spiral suggested that a vortex of gas and particles was present during operation. The reason for this perturbation of the $P B$ is 


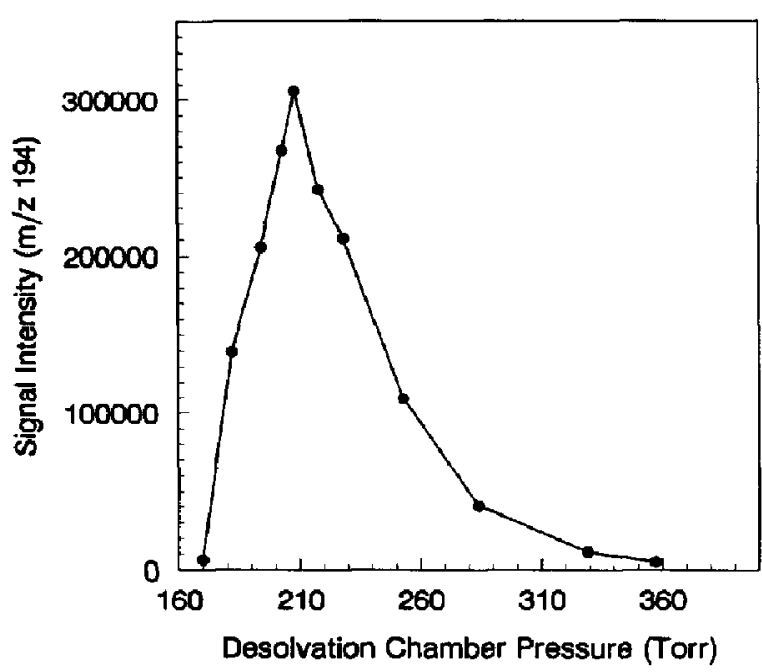

Figure 2. Effect of the helium flow through the nebulizer and into the desolvation chamber on signal intensity for $m / z 194$ of caffeine.

unknown, but all of these deposits suggest that further work is necessary to improve the transmission of the current PB interface.

\section{Observed Mass Spectra}

A high partial pressure of neutral species may result in ion-molecule reactions. Long residence times found in ion trap mass spectrometers provide sufficient time for ion-molecule reactions to occur at much lower reagent gas pressures than in a typical ion beam mass spectrometer. The partial pressure of methanol measured outside the trapping chamber was typically ca. $1 \times$ $10^{-7}$ torr (uncorrected). We expect the methanol pressure inside the trap to be approximately an order of magnitude higher. At this manifold pressure, we observe some ion-molecule reactions. At an ejection cutoff of $m / z 16$, a space-charged methanol peak at $m / z$ 33 is observed, as is a peak at $m / z$ 47. Both of these ions are attributed to methanol self-CI and ion-molecule reactions. When the low-mass cut-off is raised to $50 \mathrm{u}$, and the calibration compound FC43 is introduced in the presence of methanol, a reduced relative abundance of ions, such as $m / z 69$ and 219 , is evident. Simultaneously, an increase in abundance was observed of $m / z 15,33$, and 47 [assigned to $\mathrm{CH}_{3}^{+}$, $\mathrm{CH}_{3} \mathrm{OH}_{2}^{+},\left(\mathrm{CH}_{3}\right)_{2} \mathrm{OH}^{+}$, respectively]. Although the $\mathrm{rf}$ amplitude was set to eject all masses below $50 \mathrm{u}$ during ionization, evidently enough time exists during the analytical scan to allow this ion formation. Apparently, methanol is ionized by charge exchange and further reacts with neutrals to form these ions. Setting the rf cut-off mass to $100 \mathrm{u}$ also revealed an ion at $\mathrm{m} / \mathrm{z}$ 81 , which is possibly $\mathrm{CF}_{2} \mathrm{CH}_{3} \mathrm{OH}^{+}$. This latter ion is attributed to an ion-molecule reaction of methanol with ions in the EI FC43 spectrum above mass $100 \mathrm{u}$. We kept the ion trap rf ejection cut-off set at $m / z 50$ to remove $m / z 33$ and 47 formed during ionization and thus to reduce the effects of ion-molecule reactions and space charge for all other experiments described here.

The ion trap temperature of ca. $170^{\circ} \mathrm{C}$ is relatively low compared with other source vaporizing temperatures found in the literature for PB work [3-5, 32]. When a higher ion trap temperature was used, the signal did increase for caffeine. This is believed to be due to a more rapid vaporization process, but the background chemical noise increased to a greater extent. As a result, the ion trap was maintained at the lower temperature to produce a higher signal-to-noise ratio.

As shown in Figure 3, at normal operating conditions of the interface (see Table 1), a 20- $\mu \mathrm{L}$ volume of a $1-\mathrm{ng} / \mu \mathrm{L}$ solution of caffeine $(20 \mathrm{ng})$ in methanol gave an EI mass spectrum. The spectrum demonstrates unit mass resolution and a signal-to-noise ratio of approximately 100 for $m / z$ 194. The base peak is $m / z 194$ and the ${ }^{13} \mathrm{C}$-isotope peak is at the expected relative abundance of ca. $11 \%$. Extensive EI fragmentation is observed. Although the $\mathrm{rf}$ level was set to reject ions less than $50 \mathrm{u}, m / z 33$ is observed. This ion is evidently protonated methanol, formed after the ionization segment of the scan. Both background and analyte ions are possible ion-molecule reactants, because the $\mathrm{m} / \mathrm{z}$ 33 was seen in both the background and sample minus background spectra. Several explanations can account for the $m / z 33$ formation. This ion is most likely formed as a result of charge exchange of methanol with the analyte ion, followed by self-CI as in the FC43 experiments. The increase in the relative abundance of $m / z 33$ with the increase in caffeine concentration during the elution of a peak further supports a reaction

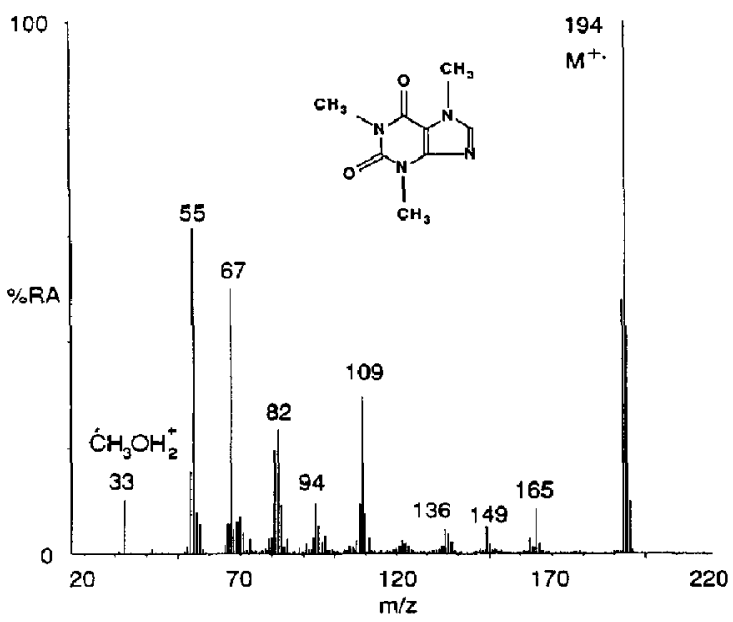

Figure 3. Electron ionization spectrum of $20 \mathrm{ng}$ of caffeine (MW 194) (50-u cut-off) Evidence of ion-molecule reactions with methanol is seen by the formation of $m / z 33$. RA, relative abundance. 
involving the analyte. Alternatively, some $m / z 33$ may arise from the formation of a proton-bound dimer $\mathrm{m} / \mathrm{z}$ 65 from methanol that undergoes dissociation to form $m / z 33$ or the dissociation of a short-lived analyte methanol adduct. These higher mass adducts, however, were not observed. The possibility of methanol self-CI during ionization is unlikely, because all ions below $m / z 50$ are ejected during this period.

The relative abundances of the ions at $\mathrm{m} / \mathrm{z} 149$ and 193 are observed to be 10 and 5 times higher, respectively, than those in the National Institute of Standards and Technology (NIST) library data for caffeine [42]. The ion at $m / z 149$ is assigned to the common ion from phthalate contamination. This ion was later found in methanol extracts of the sample vial seals. Although $m / z 193$ is characteristic of resonance-stabilized caffeine $(\mathrm{M}-\mathrm{H})^{+}$, it was also seen in the background spectra. The relative abundance of this ion with respect to $m / z 194$ decreases at higher analyte amounts and may be attributed to contamination or an unknown concentration effect. Tandem mass spectrometry (MS/MS) is suggested as a technique that would be useful in elucidating the structures of these ions. The MS/MS scan was not available for the ion trap described here.

The EI mass spectra for raffeine [molecular weight (MW) 194], 1-naphthalenol methylcarbamate (carbaryl) (MW 201), 17 $\alpha$-hydroxyprogesterone (MW 330), and reserpine (MW 608) were collected for $100 \mathrm{ng}$ of analyte. In the 100-ng caffeine spectrum, the $194^{+} / 193^{+}$ abundance ratio of 8 compares well with the NIST library data ratio of 10 . The EI carbaryl spectrum in Figure 4 shows a lack of the molecular ion at $m / z 201$; this ion is at $4 \%$ relative abundance in the NIST data. The lack of the molecular ion may be evidence of thermal decomposition. A flash varporization process at a high temperature $[32,43]$ is suggested as a method

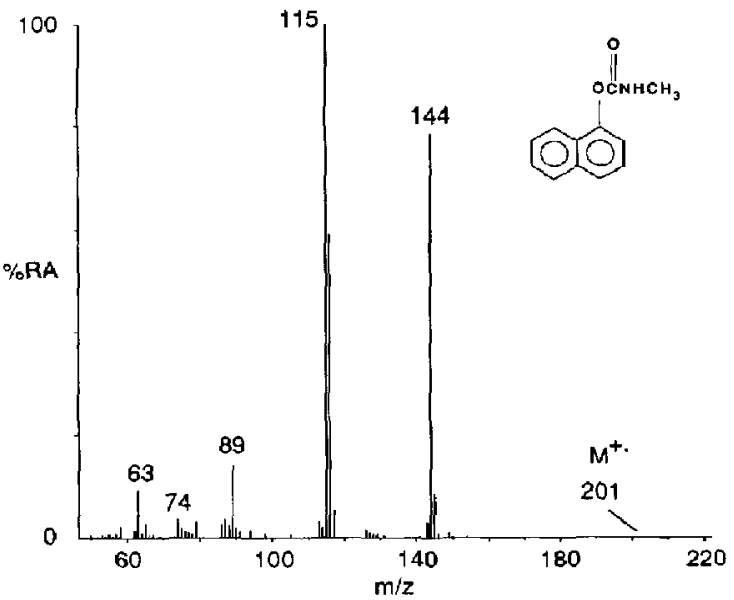

Figure 4. Electron ionization spectrum of $100 \mathrm{ng}$ of carbaryl. Possible thermal degradation of the carbamate is seen by the absence of the parent ion at $m / z, 201$. RA, relative abundance.

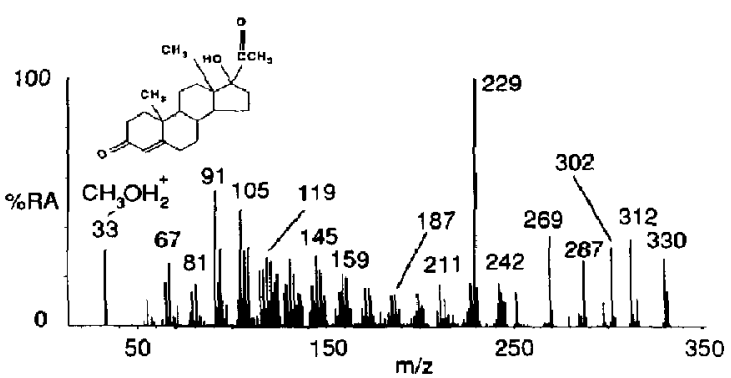

Higure 5. Electron ionization spectrum of $100 \mathrm{ng}$ of $17 \alpha$ hydroxyprogesterone (MW 330). The $m / z \quad 33$ ion is assigned to protonated methanol. RA, relative abundance.

to observe the parent ion. This, however, was not possible in the ion trap configuration shown. Figure 5 shows the EI mass spectrum of $17 \alpha$-hydroxyprogesterone. Of particular interest here is the abundance of the peaks at $m / z 331$ and 33. The $m / z 331(M+1)^{+}$ peak is at 53\% relative abundance, approximately twice the expected isotope ratio $\left({ }^{13} \mathrm{C} /{ }^{12} \mathrm{C}\right)$ for this compound. The higher ion abundance may be attributed to a contribution from $(\mathrm{M}+\mathrm{H})^{+}$. The presence of $\mathrm{m} / \mathrm{z} 33$ is again attributed to ion-molecule reactions, leading to the protonation of methanol after the ionization segment of the scan. Figure 6 shows an EI spectrum from a 100-ng injection of a higher molecular weight compound, reserpine. The base peak in this spectrum is $m / z 608$, as observed by others $[44,45]$. The relative abundance of the ${ }^{13} \mathrm{C}$ isotope is at $35 \%$, in good agreement with the calculated ${ }^{13} \mathrm{C}$ isotope relative abundance of $38 \%$. No protonation of the molecular ion is observed at this concentration.

\section{Effects of High Analyte Concentrations}

To examine the efferts of high concentrations of analyte, the $195^{+} / 194^{+}$ratio for caffeine was calculated for various amounts injected. For 20-, 100-, 500-, and 5000-ng injections, the maximum $195^{+} / 194^{+}$ratio calculated for the analytical scan with the highest ion signal was $0.12,0.22,0.42$, and 0.49 , respectively. These numbers represent the maximum ratio found. Averaging the scans over a peak will result in considerably lower ratios. These ratios show that at higher concen-

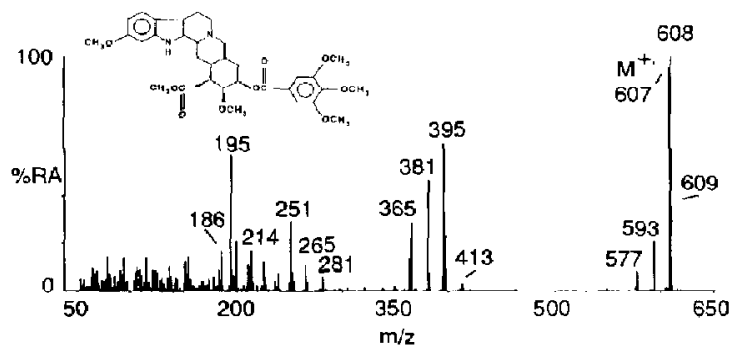

Figure 6. Electron ionization spectrum of $190 \mathrm{ng}$ of reserpine (MW 608). RA, relative abundance. 
trations of caffeine, the relative abundance of $(M+1)^{+}$ $(m / z$ 195) increases. These data are attributed to ionmolecule reactions such as self-CI $[46,67]$, leading to $(\mathrm{M}+\mathrm{H})^{+}$formation at higher analyte concentrations found both from injecting higher concentrations of analyte and from the higher analyte concentration that occurs at the maximum signal intensity of a peak. These data indicate that at higher analyte amounts, the spectrum may not be "pure EI." It is important to note that although varying the ionization time may prevent improper mass assignment that may arise from broad, space-charged peaks [48], it does not reduce the potential for self-CI [49]. Recent work using external ionization, differential pumping, and a quadrupole ion trap has shown the lack of the self-CI phenomenon [45]. The elimination of the $(\mathrm{M}+1)^{+}$peak in this latter work is believed to be due to the efficient removal of analyte neutrals.

\section{Signal-to-Noise and Peak shape}

Figure 7 demonstrates that $5 \mathrm{ng}$ of caffeine $(20-\mu \mathrm{L}$ injection of $0.25 \mathrm{ng} / \mu \mathrm{L}$ ) may be detected with a signal-to-noise of $50(\mathrm{~m} / \mathrm{z} 194)$. The peaks are $8 \mathrm{~s}$ wide FWHM and show some tailing. The average peak asymmetry factor is 2.0 [50]. Peaks from three $20-\mu \mathrm{L}$ injections of methanol are also observed, but this latter response, as well as a small fraction of the peak tailing in the 5-ng injections, is due to contamination extracted from the seals of the sample vials.

\section{Reproducibility}

An example of reproducibility was shown previously in Figure 7. The three 5-ng caffeine injections have a relative standard deviation of $2.2 \%$ for the ion $m / z$ 194. Calculation of the relative standard deviation over

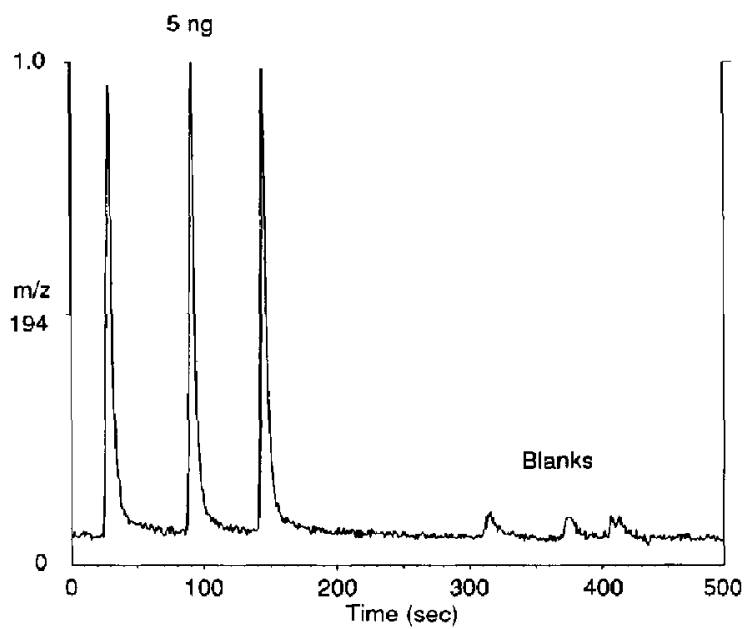

Figure 7. Three peaks of $m / z 194$ showing the detection of $5 \mathrm{ng}$ of caffeine with a signal-to-noise of 50 . The three caffeine injections are followed by three blank injections of methanol containing some contamination.

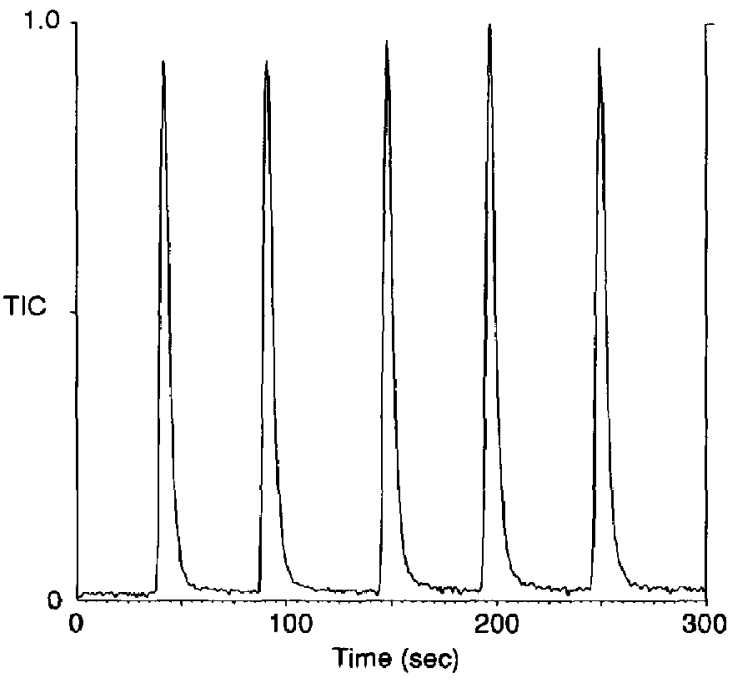

Figure 8. Five full-scan peaks of $100 \mathrm{ng}$ of carbaryl showing the repeatability of the $\mathrm{PB} /$ ion trap carbaryl. The coefficient of variance is $4.3 \%$ for the five injections. TIC, total ion current.

two months was found to be less than $40 \%$ for $20-\mu \mathrm{L}$ injections of $100 \mathrm{ng}$ of caffeine. Another example of reproducibility is shown in Figure 8 , where the fullscan total ion current from five 100-ng injections of the pesticide carbaryl is plotted. A signal-to-noise ratio of 100 is observed for each of these five peaks, with excellent peak area precision. The relative standard deviation for this set of data is $4.3 \%$.

\section{Caffeine Calibration Curve}

A calibration curve is plotted in Figure 9 for sample injections from 1 to $500 \mathrm{ng}$. A linear plot is shown in Figure 9 (solid line) with a negative ordinate intercept. Nonlinearity is observed, and the calculated correlation coefficient for the data is 0.997 . The dashed line is a polynomial fit of power 2 [51]. As shown by the dashed curve, the polynomial curve correlates well with the data above $20 \mathrm{ng}$ of caffeine. The curvature increases below $20 \mathrm{ng}$ (polynomial of power 2 for the points shown), as seen in the inset graph. The reason for the nonlinear behavior of some compounds when analyzed by PB interfaces is not well understood, and no explanation for this phenomenon is available at this time.

\section{Use of Water as the Solvent}

Experiments using $100 \%$ water as the solvent at a flow rate of $0.5 \mathrm{~mL} / \mathrm{min}$ showed that a desolvation chamber temperature of $50^{\circ} \mathrm{C}$ was unacceptable. The mass spectrum showed space charging. Fluctuations and an increase in the ion gauge readings suggest that unvaporized droplets of water were transmitted to a point 


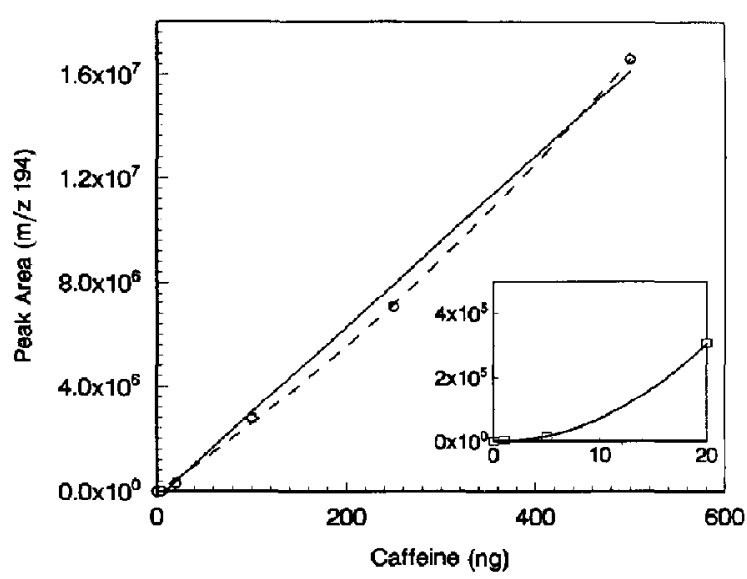

Figure 9. Linear and polynomial calibration curves for caffeine ( $m / z$ 194) from 1 to $500 \mathrm{ng}$ (see text for explanation of symbols and inset graph).

near the ion trap chamber. The increase in source pressure when using water has also been observed elsewhere [32]. At a desolvation chamber temperature of $80{ }^{\circ} \mathrm{C}$, a 100 -ng caffeine EI mass spectrum was observed at unit mass resolution. The total ion current, however, was reduced by approximately an order of magnitude compared with a caffeine in methanol mass spectrum. This analyte loss is partially attributed to inefficient evaporation of the water droplets. A loss of a factor of 8 in sensitivity is reported elsewhere for a $P B$ interface when comparing a signal from caffeine in methanol to a signal from caffeine in water [32].

\section{Conclusions}

Electron ionization spectra can be acquired from semivolatile analytes in methanol using a three-stage PB interface coupled directly to a quadrupole ion trap mass spectrometer. The data from this $\mathrm{PB} /$ ion trap system demonstrate detection limits in the nanogram range. The reproducibility of sequential injections on the $\mathrm{PB} /$ ion trap system is exceptional.

An efficient method of solvent removal, such as the three-stage $\mathrm{PB}$ interface described here, is critical to minimize the possibility of ion-molecule reactions and space charge. At methanol pressures greater than $10^{-7}$ torr, there is evidence of ion-molecule reactions. The charge exchange reaction of the solvent methanol with analyte ions (e.g., FC43 and caffeine), followed by additional ion-molecule reactions, can account for the formation of methanol product ions (e.g., $m / z 33$ and 47). A partial reduction in sensitivity may in fact be attributed to charge exchange reactions of this type. In addition to the use of the three-stage $\mathrm{PB}$ interface supplemented with helium [52], space charge due to the solvent may be prevented by operating the ion trap at a mass cut-off of $50 \mathrm{u}$ during the variable ionization times.
Self-CI occurs at higher analyte concentrations for some molecules. The self- $\mathrm{CI}$ phenomenon can be beneficial when determining molecular weights of compounds by the increased relative abundance of the protonated molecular ion. Recently, the $(M+1)^{+}$increase was eliminated by ionizing externally and injecting these ions into a differentially pumped ion trap [45]. As a result of these latter experiments, an external ionization scheme with differential pumping appears to be an advantageous alternative.

Further experiments using other solvents and analytes at various flow rates and the addition of column chromatography are needed to explore the full advantages and limitations of coupling a PB directly to a quadrupole ion trap mass spectrometer. The recent analytical capabilities of MS/MS [40, 53], mass range extension [54], and high-resolution [55] and tailored resonance-ejection techniques [56] make the coupling of a PB interface to an ion trap for liquid chromagraphy/mass spectrometry very desirable. Even without these capabilities, however, the utility and simplicity of this $\mathrm{PB}$ /ion trap system make it attractive for qualitative and, to a lessor extent, quantitative analysis.

\section{Acknowledgments}

The authors thank John T. Lopez for mechanical engineering, Delphine Wishart for illustrative work, and John N. Louris for helpful discussions.

\section{References}

1. Greene, F. T. Proceedings of the 23rd ASMS Conference on Mass Spectrumetry and Allied Topics; Houstun, TX, May 1975; p 695.

2. Greene, F. T. Proceedings of the 24th ASMS Conference on Mass Spectrometry and Allied Topics; San Diego, CA, May 1976; p 552.

3. Willoughby, R. C.; Browner, R. F. Anal. Chem., 1984, 56, 2626.

4. Winkler, P. C. Ph.D. thesis, Georgia Institute of Technology, 1986.

5. Winkler, P, C.; Perkins, D. D.; Williams, W. K.; Browner, R. F. Anal. Chem. 1988, 60, 489.

6. Browner, R. F; Winkler, P. C.; Perkins, D. D.; Abbey, L. E. Microchem. I. 1986, 34, 15.

7. Sanders, P. E.; Willoughby, R. C.; Mitrovich, S. Proceedings of the 37th ASMS Conference on Mass Spectrometry and Allied Topics; Miami Beach, FL, May 1989; p 110.

8. Kirk, J. D.; Browner, R. F. Proceedings of the 37th ASMS Conference on Mass Spectrometry and Allied Topics; Miami Beach, FL, May 1989; p 131.

9. Kirk, J. D.; Browner, R. F. Bionted. Environ. Mass Spectrom. 1989, 18, 355.

10. Llewellyn, P. M.; Littlejohn, D. P. U.S. Patent 3,429,105, February 1969.

11. Jones, P. R.; Yang, S. K. Anal. Chern. 1975, 47, 1000.

12. Bier, M. E.; Cooks, R. G. Anal. Chem. 1987, 59, 597.

13. Scott, R. P. W.; Scott, C. G.; Munroe, M.; Hess, J. J. Chromatogr. 1974, 99, 395.

14. McFadden, W. H.; Schwartz, H. L.; Evans, S. I. Chromatogr. $1976,122,389$. 
15. Van Der Greef, J.; Tas, A. C.; Ten Noever De Brauw, M. C.; Höhn, M.; Meuerhoff, G.; Rapp, U. J. Chromatogr. 1985, 323, 81.

16. Levsen, K.; Schäfer, K. H.; Dobberstein, P. Biomed. Mass Spectrom. 1984, 11, 308.

17. Games, D. E.; McDowall, M. A.; Levsen, K.; Schäfer, K. H.; Dobberstein, P.; Gower, J. L. Biomed. Mass Spectrom. 1984, 11, 87.

18. Moseley, M. A.; McGown, S. R.; Escoffier, B. H.; De Wit; Tumer, K. B.; Jurgenson, J. W. Proceedings of the 36 th ASMS Conference on Mass Spectrometry and Allied Topics; San Francisco, CA, June 1988; p 1254.

19. Bier, M. E.; Kotiaho, T; Cooks, R. G. Anal. Chim. Acta, 1990, 231,175 ,

20. Kresbach, G. M.; Baker, T. R.; Nelson, R. J.; Wronka, J.; Karger, B. L.; Vouros, P. J. Chromatogr. 1987, 394, 89.

21. Blakley, C. R.; Vestal, M. L. Anal. Chem. 1983, 55, 750.

22. Vestal, M. L. Science, 1984, 226, 275.

23. Yergey, A. L.; Edmonds, C. G.; Lewis, I. A. S,; Vestal, M. L. Liquid Chromatography/Mass Spectrometry Techniques and Applications, Plenum Press: New York, 1990.

24. Whitehouse, C.; Dreyer, R.; Yamashita, M.; Fenn, J. Anal. Chem. 1985, 57, 675.

25. Fenn, J. B.; Mann, M.; Meng, C. K.; Wong, S. F.; Whitehouse, C. M. Mass Spectrom. Rev. 1990, 9, 37.

26. Smith, R. D.; Loo, J. A.; Edmonds, C. G.; Barinaga, C. I.; Udseth, H. R. Anal. Chem. 19y0, 62, 882.

27. Ito, Y.; Takeuchi, T.; Ishi, D.; Goto, M. J. Chromatogr. 1985, $346,161$.

28. Caprioli, R.; Fan, T.; Cottrell, J. Anal. Chem. 1986, 58, 2949.

29. Teffera, Y.; Baird, W. M; Smith, D. L. Anal. Chem. 1991, 63, 453.

30. Katta, V.; Chowdhury, S. K.; Chait, B. T. Anal. Chem. 1991 63,174 .

31. Zakett, D.; Kallos, G. J.; Savickas, P. J. Proceedings of the 34th ASMS Conference on Mass Spectrometry and Allied Topics; Cincirulati, $\mathrm{OH}$, June 1986 ; $\mathrm{p} 3$.

32. Ligon, W. V.; Dom, S. B. Anal. Chem. 1990, 62, 2573.

33. Bellar, T. A.; Beymer, T. D.; Budde, W. L. J. Am. Soc. Mass Spectrom. 1990, 1, 92.

34. Bier, M. E.; Winkler, P. C.; Lopez, J. T. Proceedings of the ASMS Ion Tapping in Mass Spectrometry Conference, Sanibel Island, FL, January $1990 ; \mathrm{p} 17$.
35. J. E. Meinhard Associates, Santa Ana, CA.

36. John, J. E. A. Gas Dymamics, Allyn and Bacon: Boston, 1969.

37. Ashkenas, I I.; Sherman, F. S. In Rarefied Gas Dynamics, Vol. 2; De Leeuw, J., Ed.; Academic: New York, 1966, 84.

38. Stafford, G.; Kelley, P.; Syka, J. E. P.; Reynolds, W.; Todd, J. F. J. Int. J. Mass Spectrom. Ion Proc. 1984, 60, 85.

39. Syka, J. E. P.; Louris, J. N.; Kelley, P.; Stafford G.; Reynolds, W. U.S. Patent 4,736,101, 1988.

40. Louris, J. N.; Cooks, R. G.; Syka, J. E. P.; Kelley, P. E.; Stafford, G.; Todd, J. F. J. Anal. Chem. 1987, 59, 1677.

41. Israel, G .W.; Friedlander, S. K. J. Colloid Interface Sci. 1967, 24,330 .

42. NIST/EPA/MSDC Mass Spectral Database, April 1990.

43. Harris, W. E.; Browner, R. F. Proceedings of the 37th ASMS Conference on Mass Spectrometry and Allied Topics; Miami Beach, FL; May 1989, p. 126.

44. Browner, R. F. Microchem. J. 1989, 40, 4.

45. Bier, M. E.; Hartford, R. E.; Herron, J. R.; Stafford, G. C. Proceedings of the 39th ASMS Conference on Mass Spectrometry and Allied Topics, Nashville, TN; May 1991; p 538.

46. Ghaderi, S.; Kulkarni, P. S.; Ledford, E. B.; Wilkins, C. L.; Gross, M. L. Anal. Chem. 1981, 53, 428.

47. Olson, E. S.; Diehl, J. W. Anal. Chem. 1987, 59, 443.

48. Eichelberger, J. W.; Budde, W. L. Anal. Chem. 1987, 59, 2732.

49. McLuckey, S. A.; Glish, G. L.; Asano, K. G.; Van Berkel, G. J. Anal. Chem. 1988, 60, 2314.

50. Kirkland, J. J.; Yau, W. W.; Stoklosa, H. J.; Dilks, C. D. J. Chromatogr. Sci. 1977, 15, 303

51. Graftool, Graphical Analysis System, Version 3.3, 3-D Visions Corporation, Redondo Beach, CA.

52. Bier, M. E. U.S. Patent 5,162,650, November 1992.

53. Louris, J. N.; Brodbelt-Lustig, J. S.; Cooks, R. G.; Glish, G. L.; Van Berkel, G. J.; McLuckey, S. A. Int. J. Mass Spectrom. Ion Proc. 1990, 96, 117.

54. Kaiser, R. E.; Louris, J. N.; Anny, J. W.; Cooks, R. G. Rapid Commun. Mass Spectrom. 1989, 3, 225.

55. Schwartz, J. C.; Syka, J. E. P.; Jardine, I. J. Am. Soc. Mass Spectrom. 1991, 2, 198.

56. Julian, R. K.; Cox, K.; Cooks, R. G. Proceedings of the 40th ASMS Conference on Mass Spectrometry and Allied Topics, Washington D.C., May 1992; p. 943. 